\title{
PROBIÓTICOS NA RAÇÃO PARA O CONTROLE DE SALMONELLA MINNESOTA EM FRANGOS DE CORTE
}

\author{
Eduardo Correa Muniz ${ }^{1}$, Larissa Pickler ${ }^{1}$, Mariana Camargo Lourenço ${ }^{1}$, Patrick \\ Westphal' ${ }^{1}$, Leandro Nagae Kuritza' ${ }^{1}$, Elizabeth Santin ${ }^{1}$
}

\author{
1 UFPR \\ Correspondência: Eduardo Correa Muniz: eduardo.muniz@ufpr.br
}

\begin{abstract}
RESUMO: Foi delineado o presente estudo com o objetivo de comparar a capacidade de diferentes probióticos via ração, em reduzir a colonização de Salmonella e interferir com a dinâmica celular na mucosa intestinal em frangos desafiados com Salmonella enterica enterica sorovar Minnesota (SM). Foram utilizados probiótico A constituído de Bacillus subtillis CCT 7711, probiótico B contendo Lactobacillus acidophilus + Lactobacillus plantarium + Lactobacillus rhamnosus + Lactobacillus bulgaricus + Enterococcus faecium + Streptococcus thermophilus + Bifidobacterium bifidum, probiótico C constituído de Bacillus subtilis DSM 5750 e probiótico D Enterococcus faecium. Foi observado que todos os probióticos testados foram capazes de reduzir significativamente a contagem de Salmonella em suabes de cloaca, 48h após inoculação, com relação ao controle positivo. Todos os probióticos foram capazes de reduzir a contagem de Salmonella em ceco comparados ao controle positivo aos 35 dias. Os probióticos testados não foram capazes de reduzir a contagem de Salmonella em papo aos 35 dias de idade das aves. Na mucosa do ceco das aves, verificou-se que todos os probióticos aumentaram as células CD4+ e CD8+ em relação ao grupo controle negativo aos 7 dias de vida; apenas os probióticos $C$ e $D$ reduziram significativamente os níveis de células CD8+ na mucosa cecal de frangos aos 35 dias, em relação ao grupo controle positivo. Com base nos resultados do presente estudo, verificou-se que os probióticos, utilizados neste estudo, tiveram diferentes efeitos sobre a redução na presença de SM e também afetaram de forma diferente a dinâmica celular da mucosa cecal das aves.
\end{abstract}

Palavras-chave: células caliciformes; células CD4+; células CD8+; probióticos

\section{PROBIOTICS IN DIET TO CONTROL SALMONELLA MINNESOTA IN BROILERS}

ABSTRACT: The present study was designed to compare the ability of different probiotics, applied in feed, to reduce Salmonella colonization and interfere with the cellular dynamics in the intestinal mucosa of broilers challenged with Salmonella enterica enterica sorovar Minnesota (SM). The following probiotics were used: A composed of Bacillus subtillis CCT 7711; B containing Lactobacillus acidophilus, Lactobacillus plantarum, Lactobacillus rhamnosus, Lactobacillus bulgaricus, Enterococcus faecium, Streptococcus thermophilus, and Bifidobacterium bifidum; C consisting of Bacillus subtilis DSM 5750; and D with Enterococcus faecium. All tested probiotics were able to significantly reduce the Salmonella counts in cloacal swabs assessed at $48 \mathrm{~h}$ after inoculation when compared with the positive control. All probiotics were able to reduce the Salmonella counts in the cecum when compared to the positive control at 35 days. None of the tested probiotics reduced the Salmonella counts in the crop of broilers at 35 days of age. All probiotics induced an increase in the CD4 + and CD8+ cell counts in the cecum mucosa relative to the negative control group at 7 days of age; only probiotics $C$ and $D$, reduced significantly the CD8 + cell counts in this same tissue of broilers at 35 days compared to positive control group. The results from this study indicated that the tested probiotics presented different effects on the reduction of SM counts and affected the cell dynamics in the cecum mucosa of broilers differently.

Key Words: goblet cells; CD4+ cells; CD8+ cells, Salmonella Minnesota; probiotics 


\section{INTRODUÇÃO}

A ocorrência de doenças transmitidas por alimentos, em especial as salmoneloses, são motivo de preocupação para a indústria avícola, pois bactérias deste gênero tem sido identificadas como uma das principais causas de surtos alimentares em seres humanos. Esses microrganismos podem causar desde infecções alimentares brandas até casos fatais e seu comportamento pode variar muito de acordo com o sorovar envolvido. A espécie Salmonella enterica subespécie enterica possui mais de 2000 sorovares descritos, cuja prevalência pode variar entre localidades, estados, e países, sendo recomendado estabelecer medidas de vigilância e identificação destes sorovares em seres humanos e aves de produção, com o propósito de desenvolver programas de controle nesta área (OIE, 2011).

A Salmonella Minnesota (SM) foi isolada pela primeira vez, em 1936, em um peru de três semanas de idade de uma granja no estado de Minnesota nos EUA (Edwards e Bruner, 1938). Naquele país, entre 1996 e 2006 foram diagnosticados 340 casos de SM em casos de toxinfecção em seres humanos (Centers of Disease Control, 2008).

No último relatório anual da Agência Nacional de Vigilância Sanitária Brasileira (Anvisa, 2007), SM esteve envolvida em 1,2\% dos casos de salmoneloses, sendo que a Salmonella Enteritidis representou 0 principal sorovar isolado com $48,8 \%$. A SM também apareceu no sistema de alerta rápido da Europa, em carne de frango exportada do Brasil para a Holanda, no ano de 2008 (Rasff, 2008). Este sistema de comunicação destaca a importância da salmonelose, como barreira ao comércio internacional de alimentos.

Em trabalho de tipificação de Salmonella, em amostras positivas de frangos de corte, realizadas pelo Ministério da Agricultura do Brasil, percebeu-se elevação do percentual de SM encontrado entre o período de 2009/2010 que foi de 9,38\% comparado ao período anterior, $2004 / 2008$, onde a positividade para SM foi de 0,96\% (Freitas, 2011). Este aumento da SM foi observado, principalmente, em aves criadas na região Centro-Oeste do país mostrando que o comportamento dos diferentes sorovares tem relação com características regionais.

Um dos fatos que dificultam 0 controle deste microrganismo em plantéis avícolas refere-se à falta de sinais clínicos e/ou lesões, pois na maioria das vezes, a ave é portadora assintomática. Além disso, estudos epidemiológicos ao longo do tempo mostram que existe relação de exclusão competitiva entre diferentes sorovares. Este comportamento de alternância entre sorovares distintos indica que o nicho ecológico de um sorovar específico pode ser ocupado por outro sendo que o controle de um sorovar pode interferir na prevalência de outros (Rabsch et al., 2000).

Por todos estes aspectos, as empresas avícolas empregam um programa de biosseguridade que envolve o uso de vacinas, desinfetantes, probióticos, prébióticos e ácidos orgânicos no sentido de se controlar a Salmonelose.

Os probióticos, em especial, são produtos compostos de microrganismos vivos com capacidade de se instalar e proliferar no trato intestinal beneficiando o hospedeiro através do equilíbrio da microbiota natural e que já foram descritos como capazes de controlar Salmonella (Reid e Friendship, 2002; Dahiya et al., 2006). Os mecanismos de ação descritos para explicar o funcionamento dos probióticos são: competição por sítios de ligação (Jin et al., 1997), produção de substâncias antimicrobianas (Tagg et al., 1976; 
Lewenstein et al., 1979; Lauková et al., 2004), competição por nutrientes e estímulo ao sistema imunológico (Fuller e Gibson, 1997; Noujaim et al., 2008; Mouni et al., 2009; Lee et al., 2010).

No entanto, ainda existem muitas dúvidas sobre o mecanismo da ação de probióticos em função da grande diversidade de composição dos produtos disponíveis comercialmente, e também da interação específica entre esta microbiota e mucosa intestinal das aves.

O objetivo do presente estudo foi comparar a capacidade de diferentes probióticos comerciais na redução da excreção de Salmonella, em aves desafiadas com Salmonella enterica enterica sorovar Minnesota (SM). Além disso, foi investigado o efeito dos diferentes probióticos sobre a dinâmica de células imunológicas na mucosa intestinal de aves.

\section{MATERIAL E MÉTODOS}

Foram alojados 120 frangos de corte do $1^{\circ}$ ao $35^{\circ}$ dia de idade, divididos em delineamento inteiramente casualizado com 6 tratamentos de acordo com o Tabela 1.

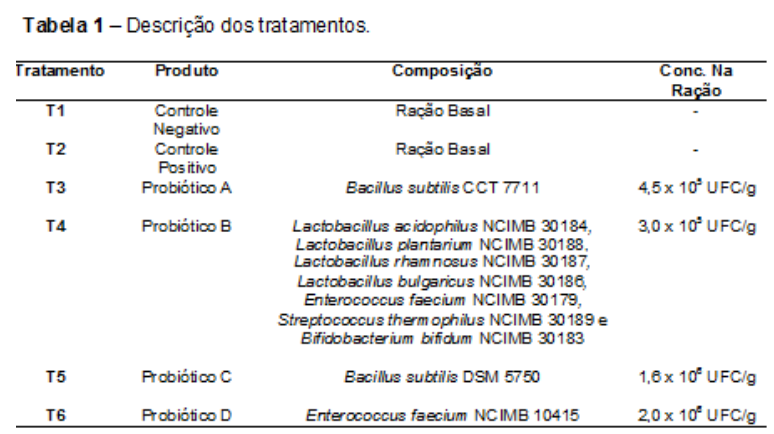

As aves de cada tratamento foram alojadas em sala, com pressão negativa, separadas, idênticas e localizadas lado a lado para evitar a contaminação entre os diferentes probióticos.

Estas salas foram previamente limpas, desinfetadas e a cama de maravalha utilizada foi previamente esterilizada em autoclave $121^{\circ} \mathrm{C} / 15$ minutos. Foi realizado teste de esterilidade nas salas, equipamentos e cama antes do inicio do experimento. $\mathrm{Na}$ chegada dos animais foi realizado eutanásia e necropsia de 5 animais para coleta de fígado e ceco e realização de análise de presença/ausência de Salmonella.

Os animais foram mantidos em temperatura ideal de conforto para a idade das aves, com fornecimento de água e ração à vontade, sendo alimentadas com dietas peletizadas e balanceadas em níveis iguais ou superiores recomendados pelo NRC (1994).

Aos 15 dias de idade os animais dos tratamentos 2 ao 6 foram inoculados com $1 \mathrm{~mL}$ de suspensão de Salmonella Minnesota na concentração $1,0 \times 10^{8} \mathrm{UFC} / \mathrm{mL}$ por via via oral.

Para o preparo do inóculo, uma colônia pura de SM, isolada de frangos de corte, foi retirada do Agar estoque e incubada em solução de $\mathrm{BHI}$ (Brain Heart Infusion) por $24 \mathrm{~h}$ a $37^{\circ} \mathrm{C}$. Esta suspensão foi diluída até a concentração 0,5 da Escala de MacFarland e aferida em espectrofotômetro, previamente descrito por Pickler et al. 2012.

Para análise microbiológica foram realizados suabes de cloaca $48 \mathrm{~h}$ após inoculação, sendo 5 amostras por tratamento (cada amostra foi um pool de 3 animais) para análise de contagem de Salmonella. Aos 7 dias de idade (5 animais por tratamento) e aos 35 dias de idade (10 animais por tratamento) foram eutanasiados, por deslocamento cervical e necropsiados para coleta de papo e ceco de forma asséptica e posterior análise de Salmonella.

Foram realizadas também coletas de fragmentos de íleo e ceco de 5 animais por tratamento fixados em formol tamponado 10\% para analise de células caliciformes e fragmentos dos mesmos segmentos congelados em 
nitrogênio liquido para posterior analise de linfócitos T CD4+ e CD8+ através de imunohistoquímica.

Para realização do procedimento de contagem de Salmonella procedeuse como Pickler et al., 2012. Os suabes de cloaca, os papos e os cecos foram diluídos em água peptonada $2 \% \mathrm{em}$ proporção de 1:9. Retirou-se $1 \mathrm{~mL}$ da solução de água peptonada $2 \%$ que foi pipetado no tubo contendo $9 \mathrm{~mL}$ de água peptonada $0,1 \%$ e assim sucessivamente até a diluição $10^{-3}$. Posteriormente retirou-se $100 \mu \mathrm{L}$ de cada diluição, plaqueou-se em duplicata em meio XLD (Xylose Lysine Desoxycholate) e com uma alça de Drigalsky estéril espalhou-se o líquido na placa. As placas foram incubadas em estufa regulada a $35^{\circ} \mathrm{C}$ por $24 \mathrm{~h}$ e submetidas à posterior contagem das colônias típicas.

A solução inicial de água peptonada $2 \%$ foi incubada a $35^{\circ} \mathrm{C}$ por $24 \mathrm{~h}$, em caso de não ter ocorrido crescimento de colônias típicas de Salmonella sp. em plaqueamento direto, retirou-se $100 \mu \mathrm{L}$ da solução inicial em água peptonada $2 \%$ e acrescentou-se em um tubo contendo $10 \mathrm{~mL}$ de caldo Rappaport-Vassiliadis, incubou-se em estufa regulada a $42^{\circ} \mathrm{C}$ por $24 \mathrm{~h}$ para confirmação da positividade ou negatividade da amostra.

Os resultados das contagens de colônias foram expressos de acordo com Procedimentos de Contagem de Colônia de acordo com a Normativa n-62 publicada em 26 de agosto de 2003 (Brasil - MAPA).

Para as análises de linfócitos $T$ CD4+ e CD8+ através de imunohistoquímica, as amostras foram incluídas em gel Tissue-Tek O. C. T. (Miles, Elkhart IN, US), congeladas em nitrogênio líquido, seccionadas com $5 \mu \mathrm{m}$ de espessura em um aparelho criostato e fixadas em lâminas carregadas positivamente em acetona $100 \%$. Em seguida foi realizada a re- hidratação com PBS $0,1 \mathrm{M}$ pH 7,6, bloqueio da peroxidase endógena com peróxido de hidrogênio $3 \%$ por 5 minutos e proteína bloqueadora por 8 minutos. Os anticorpos primários utilizados foram Anti-CD4 (CT-4 Southern Biotech 1:100) e Anti-CD8 (CT-8 Southern Biotech 1:100), incubados por 90 minutos a $37^{\circ} \mathrm{C}$. Para detecção da reação foi utilizado anticorpos secundários anticamundongo e anti-coelho combinados em sistema de amplificação, kit ADVANCE®, por 30 minutos. Para revelação da reação foi utilizado cromógeno, kit $\mathrm{DAB} B$, por 30 segundos. As lâminas foram contra-coradas com Hematoxilina de Meyer (adaptado de Jeurissen et al., 2000).

Campos microscópicos com presença de células positivas foram quantificados em microscopia de luz com ampliação de 100X (Olympus BX41 Olympus America INC., NY, USA). Foram analisados 20 campos para cada grupo experimental e para cada marcador de superfície celular.

As amostras de íleo ceco foram processadas rotineiramente para histologia e coradas com Alcian Blue. Foi avaliada a contagem de células caliciformes, com leitura de 20 campos por grupo experimental em um aumento de 100X (Olympus BX41 Olympus America INC., NY, USA) (Smirnov et al., 2004).

Foi utilizado o programa estatístico StatView for Windows Copyright $^{\odot} 1998$ (SAS Institute Inc., NC, USA). As contagens de colônias de Salmonella foram transformadas em Log 10 para análise estatística. Todos os resultados foram submetidos à ANOVA, teste de Fischer à $5 \%$ de probabilidade.

\section{RESULTADOS}

As amostras de fígado e ceco coletadas no primeiro dia e os papos e cecos coletados aos 7 dias de idade 
foram todas negativas para análise de Salmonella sp. O tratamento negativo não inoculado permaneceu negativo para SM na cama e órgãos durante todo o período indicando a eficiência do sistema de isolamento entre as câmaras que separavam os tratamentos.

Os resultados da contagem de colônias de Salmonella (média \pm desvio padrão) em suabe de cloaca 48h após inoculação, papo e ceco aos 35 dias de idade dos diferentes tratamentos estão expressos na Tabela 2. Todos os probióticos testados foram capazes de reduzir significativamente a contagem de Salmonella em suabes 48 h após inoculação com relação ao controle positivo. Além disso, todos os probióticos foram capazes de reduzir a contagem de Salmonella em ceco aos 35 dias quando comparado ao controle positivo. Por outro lado, os probióticos testados não foram capazes de reduzir a contagem de Salmonella em papo aos 35 dias de idade das aves.

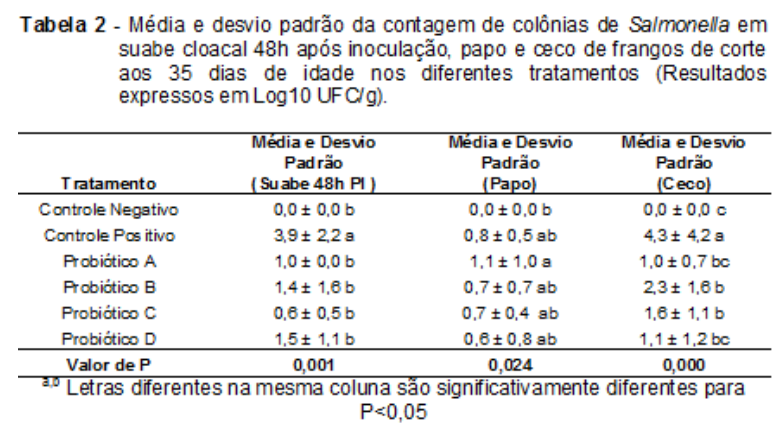

A Tabela 3 expressa os resultados da contagem de células caliciformes, células CD4+ e CD8+ na primeira coleta (7 dias de idade) em íleo e ceco de frangos de corte nos diferentes tratamentos.

Tabela 3 - Contagem (média e desvio padrão) de células caliciformes, $\mathrm{CD} 4+$ e CD8+ por campo em íleo e ceco de frangos de corte aos 7 dias de idade nos diferentes tratamentos (aumento de $100 \mathrm{X}$ ).

\begin{tabular}{|c|c|c|c|c|c|c|}
\hline \multirow[b]{2}{*}{ Tratamento } & \multicolumn{3}{|c|}{ lleo } & \multicolumn{3}{|c|}{ Ceco } \\
\hline & Caliciformes & $\mathrm{CD} 4+$ & CD8+ & Caliciformes & $\mathrm{CD} 4+$ & $\mathrm{CDB}+$ \\
\hline C. Negativo & $41,4 \pm 8,40$ & $4,3 \pm 3,7 \mathrm{~b}$ & $7,9 \pm 2,3$ & $10,3 \pm 2,30$ & $8,3 \pm 3,300$ & $10,3 \pm 4,00$ \\
\hline C. Positivo & - & - & - & - & - & - \\
\hline Probiótioo A & $62,1 \pm 6,8 \mathrm{a}$ & $5,3 \pm 3,4 \mathrm{ab}$ & $7,4 \pm 4,8$ & $14,1 \pm 2,8 \mathrm{ab}$ & $16,1 \pm 4,8 \mathrm{ab}$ & $17,3 \pm 2,7 \mathrm{a}$ \\
\hline Probiótioo B & $49,3 \pm 6,0 \mathrm{~b}$ & $9,4 \pm 4,4 \mathrm{a}$ & $6,8 \pm 4,1$ & $14,5 \pm 2,6 \mathrm{ab}$ & $19,9 \pm 3,5 \mathrm{a}$ & $15,2 \pm 3,1 a t$ \\
\hline Probiótion C & $57,2 \pm 6,9 \mathrm{a}$ & $8,8 \pm 4,5 \mathrm{ab}$ & $6,3 \pm 2,9$ & $15,7 \pm 2,5 \mathrm{a}$ & $13,0 \pm 4,5 \mathrm{bc}$ & $11,8 \pm 3,5 \mathrm{~b}$ \\
\hline Probiótion D & $62,5 \pm 5,6 \mathrm{a}$ & $4,8 \pm 2,4 a b$ & $4,9 \pm 2,0$ & $12,8 \pm 2,5 b$ & $18,4 \pm 3,5 \mathrm{a}$ & $11,7 \pm 2,8 \mathrm{~b}$ \\
\hline Valor de $P$ & $<0,001$ & 0,008 & 0.355 & $<0,001$ & $<0,001$ & $<0,001$ \\
\hline
\end{tabular}

A Tabela 4 expressa os resultados da contagem de células caliciformes e células CD4+ e CD8+ na segunda coleta (35 dias de idade) no íleo e ceco de frangos de corte nos diferentes tratamentos.

\begin{tabular}{|c|c|c|c|c|c|c|}
\hline \multicolumn{2}{|c|}{ Ceco } & \multicolumn{2}{|l|}{ lleo } & \multirow[b]{2}{*}{$\begin{array}{c}\text { Caliciforme } \\
\mathrm{s}\end{array}$} & \multirow[b]{2}{*}{$\mathrm{CD} 4+$} & \multirow[b]{2}{*}{$\mathrm{CD} 8+$} \\
\hline Tratamento & Caliciformes & $\mathrm{CD} 4+$ & $\mathrm{CD} 8+$ & & & \\
\hline C. Negativo & $64,5 \pm 14,9$ & $16,2 \pm 6,4 a$ & $6,9 \pm 4,7 \mathrm{~b}$ & $10,8 \pm 6,0$ & $19,6 \pm 6,0 \mathrm{ab}$ & $11,5 \pm 3,5 \mathrm{c}$ \\
\hline C. Positivo & $60,9 \pm 12,7$ & $15,5 \pm 5,5 \mathrm{a}$ & $11,4 \pm 6,3 \mathrm{ab}$ & $13,7 \pm 5,3$ & $23,7 \pm 8,3 \mathrm{ab}$ & $21,9 \pm 5,6 \mathrm{a}$ \\
\hline Probiótion A & $52,9 \pm 11,3$ & $12,7 \pm 4,2 \mathrm{ab}$ & $10,9 \pm 3,9 \mathrm{ab}$ & $11,5 \pm 8,0$ & $17,0 \pm 3,7 \mathrm{~b}$ & $19,9 \pm 6,1 \mathrm{ab}$ \\
\hline Probiótion B & $58,3 \pm 18,9$ & $15,7 \pm 4,3 \mathrm{a}$ & $13,3 \pm 2,8 \mathrm{a}$ & $11,9 \pm 4,4$ & $24,6 \pm 4,8 \mathrm{sb}$ & $22,4 \pm 6,2 \mathrm{a}$ \\
\hline Probiótion C & $63,0 \pm 11,5$ & $10,8 \pm 5,0 \mathrm{ab}$ & $6,8 \pm 2,5 \mathrm{~b}$ & $13,7 \pm 4,6$ & $25,3 \pm 7,9 \mathrm{a}$ & $13,1 \pm 4,2 \mathrm{bc}$ \\
\hline Probiótion D & $62,0 \pm 9,5$ & $7,9 \pm 3,9 \mathrm{~b}$ & $9,2 \pm 4,6 \mathrm{ab}$ & $12,2 \pm 4,4$ & $21,8 \pm 3,1 \mathrm{ab}$ & $14,5 \pm 4,8 \mathrm{bc}$ \\
\hline Valor de P & 0,0813 & 0,002 & 0,008 & 0,519 & 0,024 & $<0,001$ \\
\hline
\end{tabular}

\section{DISCUSSÃO}

Nurmi e Rantala (1973) foram pioneiros em descrever o uso do mecanismo chamado de exclusão competitiva (EC) no controle de Salmonella. Esses pesquisadores demonstraram que a colonização precoce com bactérias de aves adultas em aves jovens era capaz de proteger contra a colonização destas por Salmonella. Em principio esse mecanismo foi associado à produção, por parte de microorganismos oferecidos às aves jovens, de ácidos voláteis que seriam capazes de inibir o crescimento de Salmonella. Posteriormente, Soerjadi et al. (1981) demonstraram que a proteção ao desafio oral por Salmonella iniciava aparentemente 1 a 2 horas após 0 tratamento com a microbiota protetora, o que indicaria que não somente a presença de ácidos orgânicos voláteis, mas também a competição por sítios de ligação poderia ser importante no mecanismo de inibição de Salmonella.

No que se refere ao controle de $S M$, foi verificado que todos os produtos utilizados foram efetivos em diminuir a excreção de SM em suabes de cloaca de aves 48h após a inoculação em relação ao grupo inoculado que não recebeu nenhum probiótico. Em relação 
a porcentagem de redução de SM, aos 35 dias, em ceco das aves com relação ao controle positivo, foi de $76,04 \%$ no probiótico A, $46,27 \%$ no probiótico B, $62,09 \%$ no probiótico C e $73,45 \%$ no probiótico $\mathrm{D}$.

O efeito inibitório de probióticos sobre a população de enterobactérias patogênicas por meio do mecanismo de exclusão competitiva é bastante documentado na literatura (Reid e Friendship, 2002; Dahiya et al., 2006), e pode ser uma possível explicação para efeito de redução de SM observado no presente estudo pelos diferentes probióticos.

$\mathrm{Na}$ análise da dinâmica celular na mucosa intestinal de aves frente aos diferentes probióticos, foi observado que todos aumentaram a quantidade de células caliciformes na mucosa de íleo e ceco das aves aos 7 dias de idade. As células caliciformes, presentes nas vilosidades intestinais são responsáveis pela manutenção da camada de muco que atua como meio de proteção físico e biológico e também é um componente da resposta imunológica inata que é regulada em resposta à inflamação e infecção (Uni et al., 2003), assim acredita-se que a presença dos probióticos na dieta das aves pode interferir na resposta imunológica inata representada pela expressão de células produtoras de muco.

A inclusão/exclusão imunológica está relacionada com a produção de IgA pelo hospedeiro que facilita ou dificulta a adesão de bactérias na mucosa intestinal. Quando o microrganismo é benéfico ocorre uma baixa produção de $\lg A$, que se liga ao agente e facilita a adesão deste na mucosa intestinal formando um biofilme que protege contra infecção por outros microorganismos e evita a translocação dessas bactérias através da mucosa do hospedeiro (inclusão imunológica). Por outro lado, microorganismos que causam lesão, estimulam a produção de altos níveis de IgA que inibem o agente e impedem a adesão deste ao hospedeiro (exclusão imunológica). (Everret et al., 2004).

O uso de probióticos na dieta também interferiu com a presença de células CD4+ e CD8+ na mucosa intestinal das aves. Segundo Van Immerseel et al. (2002), o encontro de células epiteliais especializadas com microorganismos, rapidamente estimula a liberação de quimiocinas próinflamatórias que atraem células imunológicas inatas, como granulócitos e macrófagos, capazes de desencadear novas reações imunológicas, como o aparecimento de linfócitos $T$ auxiliares (células CD4+).

As células CD4+ estão relacionadas ao início da resposta imunológica específica, sendo estas responsáveis também pela modulação imunológica. Essas células são chamadas de linfócitos $T$ auxiliares e podem apresentar o antígeno para os Linfócitos B para a produção de anticorpos e também interferem com a imunidade celular (Fearon e Locksley, 1996). Linfócitos T citotóxicos (CD8+) estão diretamente relacionadas a eliminação de patógenos intracelulares sendo responsáveis pela imunidade celular (Zou et al., 2006).

No presente estudo, na mucosa do ceco das aves, que parece ser o sitio de maior atuação dos probióticos, verificou-se que todos aumentaram as células CD4+ em relação ao grupo controle negativo aos 7 dias de vida das ave. Quanto às células CD8+ foi verificado que os probióticos $A$ e $B$ aumentaram os níveis de células CD8+ na mucosa em relação ao grupo que não consumiu probióticos na dieta. Alguns autores (Noujaim et al., 2008; Mouni et al., 2009; Lee et al., 2010) citam que algumas bactérias como Lactobacillus e Bifidobacterium bifidum, presentes no probiótico B podem atuar 
estimulando o aumento de CD8+ específico.

Após o desafio com SM, foi observado que as aves que não consumiram os probióticos na dieta apresentaram aumento no número de células CD8+ na mucosa do ceco quando comparado ao grupo não desafiado. $\mathrm{O}$ mesmo ocorreu em aves desafiadas que foram alimentadas com A e B. Como estes produtos sozinhos foram capazes de aumentar a presença destas células na mucosa, verificado na análise de 7 dias de idade, não se pode dizer que este efeito deveu-se ao estímulo da SM sozinho (Dahiya et al., 2006).

Por outro lado, foi verificada redução de células CD8+ na mucosa do ceco das aves alimentadas com os probióticos $\mathrm{C}$ e $\mathrm{D}$ em relação ao grupo controle desafiado, e isso pode ser associado a redução de bactérias patogênicas no lúmen intestinal como visto por seu efeito sobre a presença de SM no ceco de aves alimentadas por estes probióticos. Scharek et al. (2005) observaram que redução na contagem de células CD8+ em suínos pode ser associada a redução na contagem de $E$. coli. Em verdade, os probióticos $C$ e $D$ diminuíram as células CD8+ mas aumentaram as células CD4+ e isso também pode ter interferido na resposta a SM, pois sabe-se que a células CD4+ também podem atuar na resposta imunológica humoral, pois são elas que apresentam os antígenos para os linfócitos $B$ se diferenciarem em células produtoras de anticorpos como $\lg A$.

\section{CONCLUSÃO}

Com base nos resultados do presente estudo, verificou-se que também ocorre interferência dos probióticos da dieta com respostas imunológicas na mucosa intestinal das aves. Estes resultados sugerem que o efeito dos probióticos utilizados neste estudo sobre a redução na presença de SM pode ser resultado de uma associação de mecanismo de exclusão competitiva e imunomodulação. Entretanto foram verificadas diferenças na atuação de cada probiótico sobre presença de células imunológicas na mucosa intestinal de frangos, sendo necessários maiores estudos para se compreender esse efeito imunomodulatório dos probióticos.

É possível concluir com o presente estudo que diferentes probióticos apresentam diferentes capacidades de afetar a colonização de Salmonella em aves desafiadas e alteram a dinâmica celular da mucosa cecal das aves

\section{NOTAS INFORMATIVAS}

Este projeto foi aprovado pela Comissão de Ética no uso de animais (CEUA SCA) da Universidade Federal do Paraná sob Protocolo n³4-2011.

\section{REFERÊNCIAS}

\section{AGÊNCIA NACIONAL DE VIGILÂNCIA}

SANITÁRIA - ANVISA. Relatório anual 2007.

Disponível em:

<http://www.anvisa.gov.br/alimentos/Relatorio_G GALI_2007.pdf> Acesso em: 16/08/2012.

MINISTÉRIO DA AGRICULTURA PECUÁRIA E ABASTECIMENTO - MAPA. Instrução

Normativa no62, publicada em 26 de agosto de 2003.

CENTERS OF DISEASE CONTROL - CDC. Salmonella Surveillance: Annual Summary, 2006. Atlanta, Georgia: US Department of health and Human Services, 2008, 101p.

DAHIYA, J.P.; WILKIE, D.C. ; VAN KESSEL, A.G. ; DREW, M.D. Potential strategies for controlling necrotic enteritis in broiler chickens in post-antibiotic era. Animal Feed Science and Technology, v.129 n.1-2, p.60-88, 2006.

EDWARDS, P.R.; BRUNER, D.W.. Two new Salmonella isolated from Fowls. Journal of Hygiene, v.38, n.6, p.716-720, 1938.

EVERETT, M.L.; PALESTRANT, D.; MILLER, S.E.. Immune exclusion and immune inclusion: A new mode of host-bacterial interactions in the 
gut. Clinical and Applied Immunology

Reviews, v.4, p.321-332, 2004.

FEARON, D.T.; LOCKSLEY, R.M.. The instructive role of innate immunity in the acquired immune response. Science, v.272, p.50-54, 1996.

FREITAS, J. Evolução de sorovares Modelo de banco de cepas. In: Seminário Internacional de Salmoneloses Aviárias. 2011. Rio de Janeiro, RJ. Anais. Campinas:UBABEF, 2011, CD-ROM

FULLER, R.; GIBSON, G.R.. Modification of the intestinal microflora using probiotics and prebiotics. Scandinavian Journal of Gastroenterology, v.32, supl.222, p.28-31, 1997.

JEURISSEN, A.H.M.; CLAASSEN, E.; BOONSTRA-BLOM, A.G. et al.

Immunocytochemical techniques to investigate the pathogenesis of infectious micro-organisms and the concurrent immune response of the host. Comparative Immunology, Microbiology \& Infectious Diseases, v.24, p.141-151, 2000.

JIN, L.Z.; HO, Y.W.; ABDULLAH, N.; JALALUDIN, S.. Probiotics in poultry: modes of action. World's Poultry Science Journal, v.53, p.351-68, 1997.

LAUKOVÁ, A.; GUBA, P.; NEMCOVÁ, R.; MAREKOVÁ, M.. Inhibition of Salmonella enterica serovar Düsseldorf by enterocin $A$ in gnotobiotic Japanese quails. Veterinary Medicine Czech, v.49, p.47-51, 2004.

LEE, K.; LILLEHOJ, H.S.; SIRAGUSA, G.R.. Direct-fed microbials and their impact on the intestinal microflora and immune system of chickens. Journal of Poultry Science, v.47, p.106-114, 2010.

LEWENSTEIN, A.; FRIGERIO, G.; MORONI, M.. Biological properties of sf68, a new approach for the treatment of diarrhoeal diseases. Current Therapy Research, v.26, p.967-981, 1979.

MOUNI, F.; AISSI, E.; HERNANDEZ, J. et al. Effect of Bifidobacterium bifidum DSM 20082 cytoplasmatic fraction on human immune cells. Immunological Investigation, v.38, n.1, p.10415, 2009.

NATIONAL RESEARCH COUNCIL - NRC. Nutrient requirements of poultry. 9th rev. ed. National Academy Press: Washington, D.C, 1994.

NOUJAIM, J.C.; ANDREATTI FILHO, R.L.; LIMA, E.T. et al. Detection of T lymphocytes in intestine of broiler chicks treated with Lactobacillus spp. and challenged with Salmonella enterica serovar Enteritidis. Poultry Science, v.87, n.3, p.927-933, 2008.
NURMI, E. V.; RANTALA, M.. New aspects of Salmonella infection in broiler production. Nature, n.241, p.210, 1973.

OFFICE INTERNATIONAL DES EPIZOOTIES OIE. World Organisation for Animal Health , 2011. Terrestrial Animal Health Code. $21^{\circ}$ ed. 435 p. Disponível em: <http://www.oie.int/doc/ged/D10905.PDF>. Acesso em: 16/08/2012.

PICKLER, L.; HAYASHI, R.M.; LOURENÇO, M.C. et al. Avaliação microbiológica, histológica e imunológica de frangos de corte desafiados com Salmonella Enteritidis e Minnesota e tratados com ácidos orgânicos. Pesquisa Veterinária Brasileira, v.32, n.1, p.27-36, 2012.

RABSCH, W.; HARGIS, B.M.; TSOLIS, R.M. et al. Competitive Exclusion of Salmonella Enteritidis by Salmonella Gallinarum in poultry. Emerging Infectious Diseases, v.6, n.5, p.443448, 2000.

RAPID ALERT SYSTEM FOR FOOD AND FEED - RASFF. The rapid alert system for food and feed. Annual report, 2008. Disponível em:

<http://ec.europa.eu/food/food/rapidalert/report2 008_en.pdf>. Acesso em: 16/08/2012.

REID, G.; FRIENDSHIP R. 2002. Alternative to antibiotic use: probiotics for the gut. Animal Biotechnology, v.13, n.1, p.97-112, 2002.

SCHAREK, L.; GUTH, J.; REITER, K. et al. Influence of a probiotic Enterococcus faecium strain on development of the immune system of sows and piglets. Veterinary Immunology and Immunopathology, v.105, p. 51-161, 2005.

SMIRNOV, A.; SKLAN, D.; UNI, Z.. Mucin dynamics in the chick small intestines are altered by starvation. The Journal of Nutrition, v.134, n.4, p.736-742, 2004.

SOERJADI, A.S.; STEHMAN, S.M.; SNOEYENBOS, G.H. et al. Some

measurements of protection against paratyphoid Salmonella and Escherichia coli by competitive exclusion in chickens. Avian Diseases, v.24, p.706-712, 1981.

TAGG, J.R.; DAJANI, A.S.; WANNAMAKER, L.W.. Bacteriocins of gram-positive bacteria. Bacteriological Reviews, v.40, n.3, p.722-56, 1976.

UNI, Z.; SMIRNOV, A.; SKLAN, D.. Pre- and Post hatch development of goblet cells in the broiler small intestine: effect of delayed access to feed. Poultry Science, v.82, n.2, p.320-327, 2003.

VAN IMMERSEEL, F.; BUCK, J.; SMET, I. et al. The effect of vaccination with a Salmonella 
enteritidis aroA mutant on early cellular responses in caecal lamina propria of newlyhatched chickens. Vaccine, v.20, p.3034-3041, 2002.

ZOU, F.C.; JIANG, Y.P.; NIE, K. et al. Dynamic changes of CD4+ and CD8 T lymphocyte subpopulations in blood of chicks infected with Eimeria tenella. Poultry Husbandry Diseases

Control, v.10, n.1,p.4-7, 2006. 